\title{
Erratum
}

\section{Erratum: Kieran et al., “Control of Motoneuron Survival by Angiogenin”}

In the article "Control of Motoneuron Survival by Angiogenin," by Dairín Kieran, Jordi Sebastia, Matthew J. Greenway, Matthew A. King, Dervla Connaughton, Caoimhin G. Concannon, Beau Fenner, Orla Hardiman, and Jochen H. M. Prehn, which appeared on pages 14056-14061 of the December 24, 2008 issue, there were problems with Figures 1 and 2. The authors state: "An error occurred in the assembly of control lanes in Figures $1 F$ (total Akt) and $2 D$ ( $\beta$-actin), which show similarity to lanes in a previous publication (Kieran et al., 2007). Because of the age of the earlier article, the authors were not able to access archival data or contact former staff who worked on the project. The authors repeated the experiments conducted in NSC34 cells that reproduced that wild-type angiogenin, but not K40I mutant angiogenin, activates Akt, indicated by pAkt immunoblotting in NSC34 cells. These experiments included additional controls (positive control: FGF-2) and demonstrated that total Akt levels do not change on treatment with wild-type angiogenin (see corrected Fig. 2D). The authors apologize for the duplication of the total Akt blot from the primary neuron culture experiment shown in Figure $1 F$. The data themselves stand based on the findings in NSC34 cells that wild-type angiogenin does not alter total Akt levels."

The corrected Figure 2 and its caption appear below. This correction does not affect the conclusions of the article.

\section{Reference}

Kieran D, Woods I, Villunger A, Strasser A, Prehn JH (2007) Deletion of the BH3-only protein puma protects motoneurons from ER stress-induced apoptosis and delays motoneuron loss in ALS mice. Proc Natl Acad Sci U S A 104:20606-20611. 

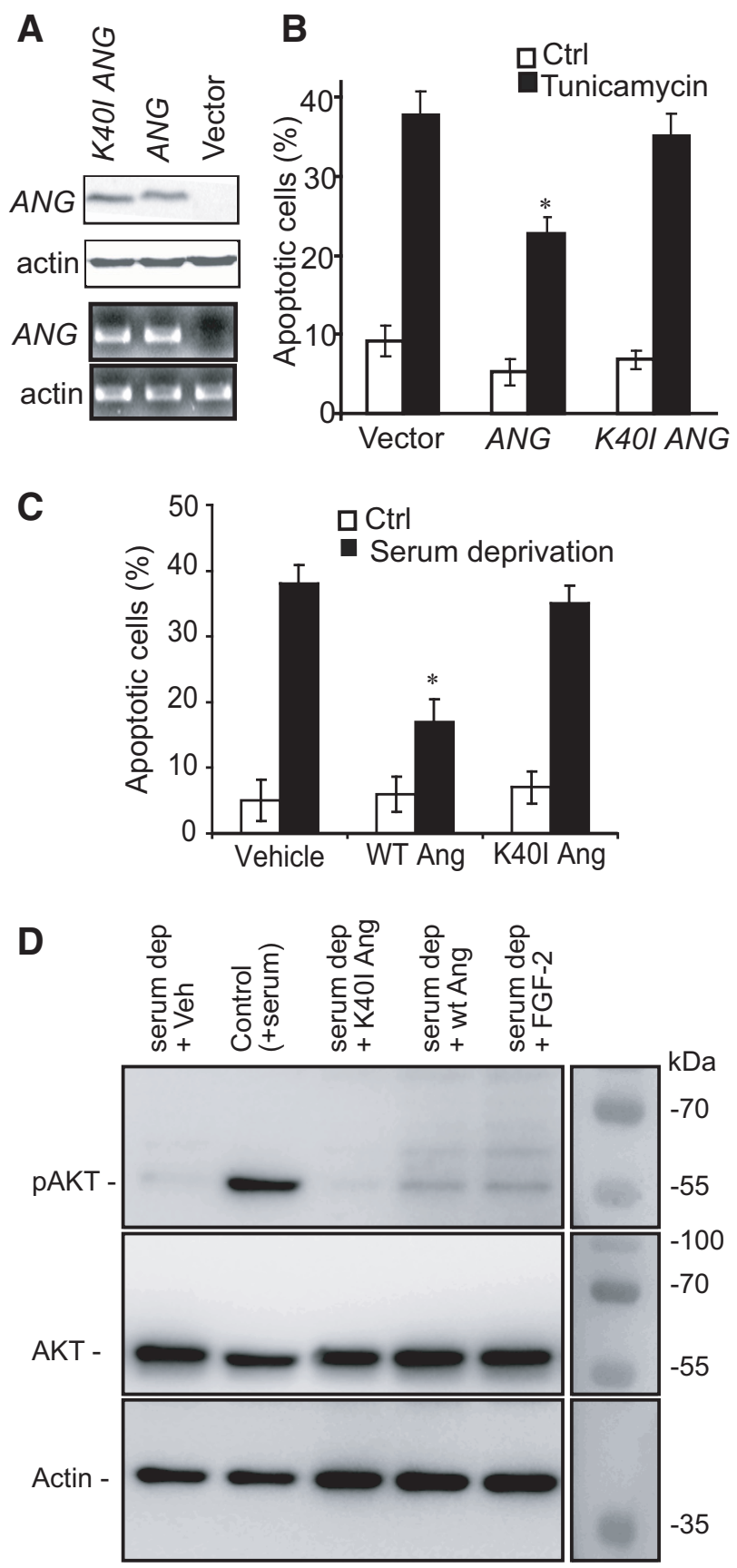

Figure 2. Lack of activity of the ALS-associated ANG mutants and potentiation of stress-induced cell injury by ANG knockdown. $\boldsymbol{A}$, Western blot (two top panels) and quantitative real-time PCR analysis (two bottom panels) showing human ANG levels in NSC-34 cells transiently transfected with pIRES-DsRed2 constructs alone, or containing either ANG or K40I mutant ANG. B, NSC34 cells transiently transfected with pIRES-DsRed2/ANG are more resistant to tunicamycin-induced ER stress $(500 \mathrm{~nm}, 24 \mathrm{~h})$ than cells transfected with K40I ANG or with empty vector. Apoptotic cell death was assessed after Hoechst 33258 staining $(* p<0.01$ vs treated empty vector, mean \pm SEM, $n=7-10)$. C, Wild-type recombinant angiogenin protein protects NSC34 cells from serum deprivation-induced toxicity $(24 \mathrm{~h}$ ), while mutant $\mathrm{K} 40 \mathrm{l}$ angiogenin protein shows no protective effect $(* p<0.01$, mean $\pm \mathrm{SEM}, n=7-10)$. $\boldsymbol{D}$, Wild-type angiogenin protein, but not K40I mutant angiogenin protein, elevated the levels of pAkt-1 in NSC34 cells during trophic factor withdrawal. NSC34 cells were subjected to serum deprivation for $2 \mathrm{~h}$, and treated with vehicle, wild-type or mutant angiogenin protein (100 ng/ml), or fibroblast growth factor-2 (FGF-2; $100 \mathrm{ng} / \mathrm{ml}, 10 \mathrm{~min}$; included as a positive control). 